\title{
Pengaruh Diesel Particulate Filter Tipe Honeycomb Berbahan Tembaga Terhadap Performa Mesin Diesel Empat Langkah
}

\author{
Sudirman Rizki Ariyanto ${ }^{1 *}$, Warju $^{2}$, Soeryanto ${ }^{3}$, Anggara Sukma Ardiyanta ${ }^{4}$ \\ ${ }^{1,4}$ Program Studi Pendidikan Vokasional Teknologi Otomotif, Universitas Bhinneka PGRI Tulungagung \\ 2,3 Jurusan Teknik Mesin, Universitas Negeri Surabaya \\ ${ }^{1,4}$ Jl. Mayor Sujadi No.7, Manggisan, Plosokandang, Kec. Kedungwaru, Kabupaten Tulungagung, 66229, Indonesia \\ ${ }^{2,3} \mathrm{Jl}$. Ketintang, Ketintang, Kec. Gayungan, Kota Surabaya, 60231, Indonesia \\ E-mail: sudirman@stkippgritulungagung.ac.id1, warju@unesa.ac.id² ${ }^{2}$,soeryanto@unesa.ac.id², \\ anggara@stkippgritulungagung.ac.id ${ }^{4}$
}

\begin{tabular}{ll}
\hline \hline & Abstrak \\
\hline Info Naskah: & Penelitian ini bertujuan menganalisis kemampuan DPF tipe honeycomb berbahan \\
Naskah masuk: 8 Juni 2020 & tembaga terhadap perfoma mesin kendaraan mesin diesel. Objek penelitian adalah \\
Direvisi: 3 Agustus 2020 & mesin Isuzu Panther tahun 1996 yang dilengkapi satu knalpot standar dan tiga knalpot \\
Diterima: 13 Agustus 2020 & eksperimen berteknologi DPF dengan variasi mesh ukuran 20, 15, dan 10 mm. Temuan \\
& penelitian ini adalah DPF 10 mm menjadi variasi terbaik bila dibandingkan dengan dua \\
& variasi lainnya dalam hal peningkatan performa mesin. Alasannya adalah semakin \\
& kecil mesh maka penjebakan partikel debu halus akan semakin baik. Di samping itu, \\
& temperatur di dalam DPF juga menjadi semakin meningkat. Selain itu, penggunaan \\
& desain casing yang tepat akan membuat turbulensi aliran gas buang menjadi lebih \\
& rendah. Selanjutnya, temperatur yang terus meningkat dan rendahnya turbulensi aliran \\
& gas buang akan menyebabkan terjadinya self-burning di dalam DPF. Terjadinya self- \\
& burning akan berdampak pada semakin sempurnanya proses pembakaran yang \\
& berdampak pada peningkatan torsi dan daya mesin masing-masing sebesar 2,29- \\
& $11,68 \%$ dan 2,94-11,93\%. jika dibandingan dengan knalpot standar.
\end{tabular}

\begin{tabular}{ll}
\hline Keywords: & Abstract \\
diesel particulate filter; & This study aims to analyze the ability of the copper honeycomb type DPF to the engine \\
PM emissions; & performance of diesel engines. The object of research was the 1996 Isuzu Panther \\
torque; & engine, which was equipped with one standard exhaust and three experimental \\
power; & exhausts with DPF technology with a variety of mesh sizes 20, 15 , and 10 mm. The \\
isuzu panther 1996. & the other two variations in terms of increasing engine performance. The reason is that \\
& the smaller the mesh, the better the trapping of fine dust particles. Besides, the \\
& temperature inside the DPF is also increasing. Also, the use of the right casing design \\
& will make the turbulence of the exhaust gas flow lower. Furthermore, the temperature \\
& continues to grow, and the little turbulence of the exhaust gas flow will cause self- \\
burning in the DPF. The occurrence of self-burning will have an impact on the \\
complete combustion process, which affects increasing torque and engine power by \\
$2.29-11.68 \%$ and $2.94-11.93 \%$, respectively, when compared with standard exhaust.
\end{tabular}

*Penulis korespondensi:

Sudirman Rizki Ariyanto

E-mail: sudirman@ stkippgritulungagung.ac.id 


\section{Pendahuluan}

Pertumbuhan kendaraan yang terus meningkat secara signifikan tentunya memberikan berbagai dampak positif dan negatif baik bagi lingkungan maupun kehidupan manusia [1]. Bagi negara, semakin banyak kendaraan bermotor yang terjual maka berdampak positif terhadap banyaknya masyarakat yang membayar pajak kendaraannya [2]. Sedangkan bagi masyarakat, dengan banyaknya ketersediaan kendaraan bermotor yang dilengkapi dengan berbagai fitur canggih tentunya akan sangat membantu masyarakat dalam melakukan aktivitas sehari-hari [3].

Dampak positif yang didapatkan dari penggunaan kendaraan bermotor tersebut sayangnya masih belum sebanding dengan dampak negatif yang harus diterima. Salah satu dampak negatif yang wajib diwaspadai adalah meningkatnya kadar polusi udara yang keluar dari ujung knalpot [4]. Ini dikarenakan apabila emisi gas buang sampai terhirup oleh manusia maka akan berpotensi menimbulkan berbagai macam penyakit berbahaya bagi kesehatan. Apabila terpapar dalam jangka pendek manusia akan mengalami mata perih, gangguan pernapasan, tenggorokan gatal, hingga pusing [5]. Namun, apabila terpapar dalam jangka panjang akan berpotensi menimbulkan penyakit berbahaya seperti gangguan jantung, kanker, paru-paru, hingga mengalami gangguan fungsi ginjal [6].

Telah banyak inovasi teknologi yang diciptakan untuk meminimalisir dampak negatif dari emisi gas buang kendaraan bermotor. Dobrzyńska dkk, menyatakan bahwa terdapat tiga cara yang dapat dilakukan untuk menekan jumlah emisi gas buang kendaraan bermotor seperti memodifikasi desain mesin, memberikan treatment pada gas buang, dan menggunakan bahan bakar tanpa timbal [7]. Salah satu cara yang saat ini banyak digunakan adalah dengan memasang teknologi diesel particulate filter (DPF) atau diesel particulate trap (DPT) pada knalpot kendaraan bermesin diesel.

Hasil dari penggunaan teknologi tersebut terbukti sangat efektif dalam hal mereduksi emisi gas buang khususnya emisi PM (Particulate Matter). Ariyanto \& Warju melalui hasil penelitiannya menunjukkan bahwa dengan menggunakan diesel particulate trap (DPT) tipe metallic honeycomb berbahan stainless-steel terbukti mampu mereduksi emisi PM hingga 89\% [8]. Kemudian, Ariyanto \& Warju melalui hasil penelitian lanjutannya menunjukkan bahwa dengan menggunakan diesel particulate trap (DPT) tipe metallic honeycomb berbahan tembaga terbukti mampu mereduksi emisi PM hingga $88 \%$ [9].

Penelitian lanjutan dilakukan oleh Muliatna, Wijanarko, \& Warju yang menunjukkan bahwa dengan menggunakan diesel particulate trap (DPT) tipe metallic honeycomb dengan bahan berbeda yakni kuningan juga terbukti mampu mereduksi emisi PM hingga 82\% [10]. Sedangkan, Ghufron \& Warju melakukan penelitian diesel particulate filter (DPF) dengan tipe wire mesh berbahan stainless-steel, hasilnya emisi PM mampu direduksi hingga mencapai 82,2\% [11].
Berdasarkan hasil penelitian terdahulu dapat kita ketahui bahwa kemampuan DPF dalam mereduksi emisi PM tidak dapat diragukan lagi. PM dapat tereduksi secara maksimal karena banyak partikel debu halus yang terjebak di dalam DPF [12]. Melalui cara tersebut, gas buang yang keluar menuju lingkungan menjadi lebih bersih dan ramah lingkungan [8]. Namun efek lain yang didapatkan adalah meningkatnya tekanan pada sistem pembuangan akibat dari terus berkumpulnya partikel debu halus di dalam DPF. Penambahan DPF pada knalpot kendaraan mesin diesel, tekanan balik (pressure drop) akan meningkat dari 0,02 atm pada $1000 \mathrm{rpm}$ menjadi $0,15 \mathrm{~atm}$ pada $4500 \mathrm{rpm}$ [13]. Hal tersebut tentunya akan berdampak pada semakin borosnya bahan bakar untuk mengkompensasi berkurangnya performa mesin pada kendaraan bermesin diesel.

Merujuk dari hasil penelitian terdahulu dan teori-teori relevan di atas, peneliti melakukan penelitian lanjutan yang khusus untuk menganalisis dampak penggunaan DPF terhadap performa mesin diesel empat langkah. Oleh karena itu, tujuan utama penelitian ini adalah untuk menganalisis lebih lanjut kemampuan DPF tipe honeycomb berbahan tembaga terhadap perfoma mesin (torsi dan daya) pada mesin diesel

\section{Metode}

Penelitian ini menggunakan mesin Isuzu Panther tahun 1996 sebagai objek penelitian yang dilengkapi satu knalpot standar dan tiga knapot eksperimen berteknologi DPF tipe honeycomb dengan variasi mesh ukuran 20, 15, dan $10 \mathrm{~mm}$ yang ditunjukan pada Gambar 1. Selain itu, desain casing DPF mengacu pada desain yang telah dibuat oleh A. Graham Bell [14]. Dalam desain tersebut disarankan agar sudut kemiringan pada entry taper sebesar $10^{\circ}$, sedangkan untuk sudut kemiringan pada exit taper dibuat sebesar $15^{\circ}$ untuk meminimalisir turbulensi aliran gas buang sebagaimana yang ditunjukkan Gambar 2 .

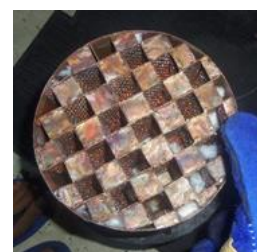

(a)

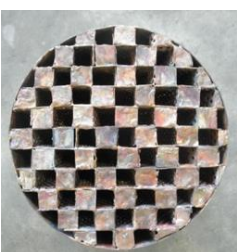

(b)

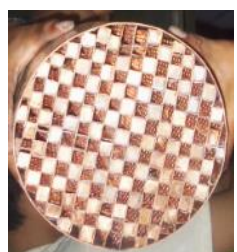

(c)
Gambar 1. Desain DPF Tipe Honeycomb dengan Variasi Mesh Ukuran (a) $20 \mathrm{~mm}$, (b) $15 \mathrm{~mm}$, dan (c) $10 \mathrm{~mm}$

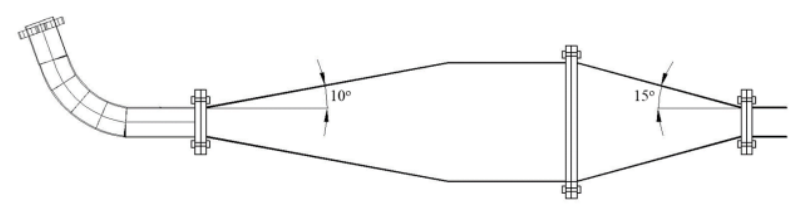

Gambar 2. Desain Casing DPF Tipe Honeycomb 
Spesifikasi dari objek penelitian dapat dilihat pada Tabel 1. Instrumen dan peralatan penelitian dapat dilihat
Tabel 3. Data Pengujian Torsi

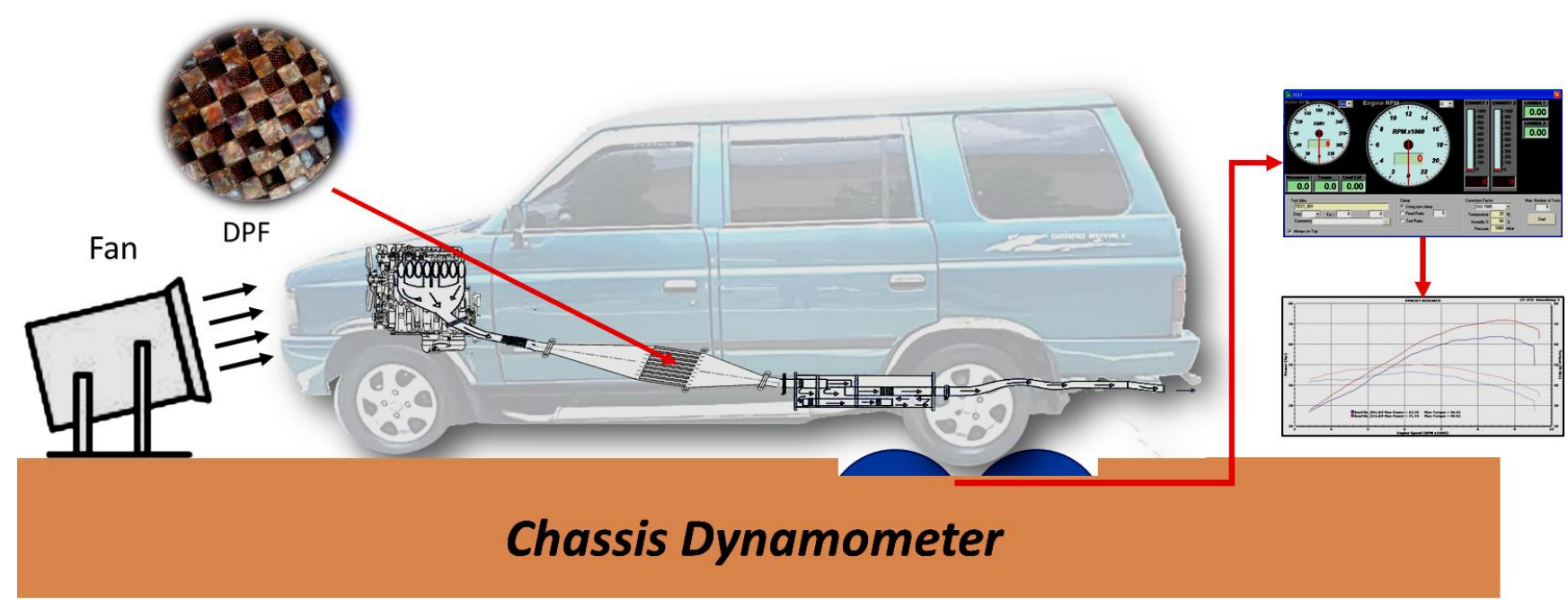

Gambar 3. Instrumen Penelitian

pada Error! Reference source not found.. Sedangkan spesifikasi instrumen dan peralatan penelitian ditunjukkan Tabel 2.

\begin{tabular}{llll}
\multicolumn{4}{c}{ Tabel 1. Spesifikasi Objek Penelitian } \\
\hline \multicolumn{3}{c}{ Spesifikasi } & \multicolumn{1}{c}{ Keterangan } \\
\hline 1. & Kapasitas mesin & $:$ & Empat silinder 2238 cc \\
2. & Kode mesin & $:$ & C223 \\
3. & Daya maksimum & $:$ & 73 PS pada putaran $4300 \mathrm{rpm}$ \\
4. & Torsi maksimum & $:$ & 140 N·m pada putaran $2400 \mathrm{rpm}$ \\
5. & Bahan bakar & $:$ & Solar \\
\hline
\end{tabular}

Tabel 2. Spesifikasi Instrumen dan Peralatan Penelitian

\begin{tabular}{cccc}
\hline Spesifikasi & & $\begin{array}{c}\text { Chassis } \\
\text { Dynamometer }\end{array}$ & Fan \\
\hline Merek & $:$ & Dynostar & Krisbow \\
Tipe & $:$ & RC3300 & EF-50S \\
Voltage/power & $:$ & $230 \mathrm{~V}, 22 \mathrm{~A}$ & $230 \mathrm{~V}, 60 \mathrm{~A}$ \\
Maks. kecepatan & $:$ & $250 \mathrm{kmh}$ & $1200 \mathrm{rpm}$ \\
\hline
\end{tabular}

Untuk mendapatkan data yang valid dan reliabel, pengujian performa mesin diesel (torsi dan daya) dilakukan berdasarkan SAE J1349 [15]. Metode pengujian dilakukan pada kondisi throttle dibuka secara penuh hingga mencapai putaran maksimum (full open throttle valve). Pengujian minimal dilakukan sebanyak tiga kali untuk memastikan data penelitian yang didapatkan valid dan reliabel.

\section{Hasil dan Pembahasan}

\subsection{Torsi}

Berdasarkan data hasil penelitian telah terbukti bahwa penggunaan DPF tipe honeycomb mampu meningkatkan torsi di setiap variasi mesh. Data pengujian torsi terlihat sebagaimana yang ditunjukkan oleh Error! Reference source not found.

\begin{tabular}{ccccc}
\hline \multirow{2}{*}{$\begin{array}{c}\text { Putaran Mesin } \\
\text { (RPM) }\end{array}$} & $\begin{array}{c}\text { Torsi }(\mathbf{N} \cdot \mathbf{m}) \\
\text { Standar } \\
(\mathbf{N} \cdot \mathbf{m})\end{array}$ & $\begin{array}{c}\mathbf{D P F} \\
\mathbf{2 0 ~} \mathbf{~ m m} \\
\mathbf{( N \cdot m )}\end{array}$ & $\begin{array}{c}\mathbf{D P F} \\
\mathbf{1 5} \mathbf{~ m m} \\
\mathbf{( N \cdot m )}\end{array}$ & $\begin{array}{c}\mathbf{D P F} \\
\mathbf{1 0} \mathbf{~ m m} \\
(\mathbf{N} \cdot \mathbf{m})\end{array}$ \\
\hline 1250 & 28,5 & 29,5 & 29,5 & 30 \\
1500 & 31 & 31,5 & 32 & 32,5 \\
1750 & 30 & 30 & 31,5 & 32,5 \\
2000 & 28,5 & 28,5 & 30 & 31 \\
2250 & 27,5 & 27,5 & 28 & 29 \\
2500 & 25 & 25 & 26,5 & 27,5 \\
2750 & 23,5 & 24 & 24,5 & 25 \\
3000 & 22 & 22,5 & 23 & 23,5 \\
3250 & 20 & 20 & 21 & 22 \\
3500 & 17,5 & 17,5 & 18 & 19,5 \\
3750 & 15 & 15 & 16,5 & 17 \\
4000 & 12,5 & 12,5 & 13,5 & 14,5 \\
4250 & 8,5 & 9 & 10 & 10,5 \\
4500 & 6 & 7 & 7,5 & 8 \\
\hline
\end{tabular}

Adapun grafik perbandingan torsi antara knalpot standar dan ketiga variasi mesh DPF tipe honeycomb dapat dilihat pada Gambar 4. Dari grafik Gambar 4, dapat kita lihat bahwa besarnya torsi awal yang dibutuhkan sebanding dengan beban yang ditopang oleh suatu kendaraan. Namun, jika dianalisa lebih jauh terlihat bahwa ada perbedaan torsi yang dihasilkan antara knalpot standar dan ketiga variasi mesh DPF tipe honeycomb. Secara umum nampak terjadi peningkatan torsi disetiap variasi mesh DPF tipe honeycomb bila dibandingkan dengan knalpot standar. Pada DPF mesh $20 \mathrm{~mm}$, torsi meningkat rata-rata sebesar $2.29 \%$ bila dibandingkan dengan knalpot standar. Selanjutnya, pada DPF mesh $15 \mathrm{~mm}$ torsi meningkat rata-rata sebesar $7.29 \%$ bila dibandingkan dengan knalpot standar. Kemudian, rata-rata peningkatan torsi terbaik ada pada DPF mesh $10 \mathrm{~mm}$ dengan nila persentase sebesar $11.68 \%$ bila dibandingan dengan knalpot standar. 
Penyebab utama terjadinya peningkatan torsi adalah adanya material glasswool yang terpasang pada DPF tipe honeycomb. Material tersebut memungkinkan memberi efek tekanan balik akibat adanya proses penyaringan emisi PM. Dengan demikian, hasil dari tekanan balik tersebut berpengaruh terhadap peningkatan suhu pada ruang bakar yang kemudian berdampak pada peningkatan torsi kendaraan [16]. Penelitian ini sejalan dengan hasil penelitian Muliatna, Susila, \& Warju (2018) yang menyebutkan bahwa penggunaan diesel particulate trap (DPT) tipe wire mesh berbahan dasar stainless-steel mampu meningkatkan torsi kendaraan meskipun tidak signifikan dengan persentase antara 4,92\% hingga 12,08\% [17]. Di samping itu, torsi yang dihasilkan setelah menggunakan
DPF tipe honeycomb relatif lebih rendah bila dibandingkan dengan DPT tipe wire mesh yang menghasilkan persentase torsi rata-rata terbaik sebesar $12,08 \%$ bila dibandingkan dengan knalpot standar.

\subsection{Daya}

Berdasarkan data hasil penelitian selain terbukti mampu meningkatkan torsi kendaraan, DPF tipe honeycomb juga terbukti mampu meningkatkan daya (power) disetiap variasi mesh. Data pengujian daya terlihat sebagaimana yang ditunjukkan oleh Tabel 4. Adapun grafik perbandingan daya antara knalpot standar dan ketiga variasi mesh DPF tipe honeycomb dapat dilihat pada

Gambar 5.

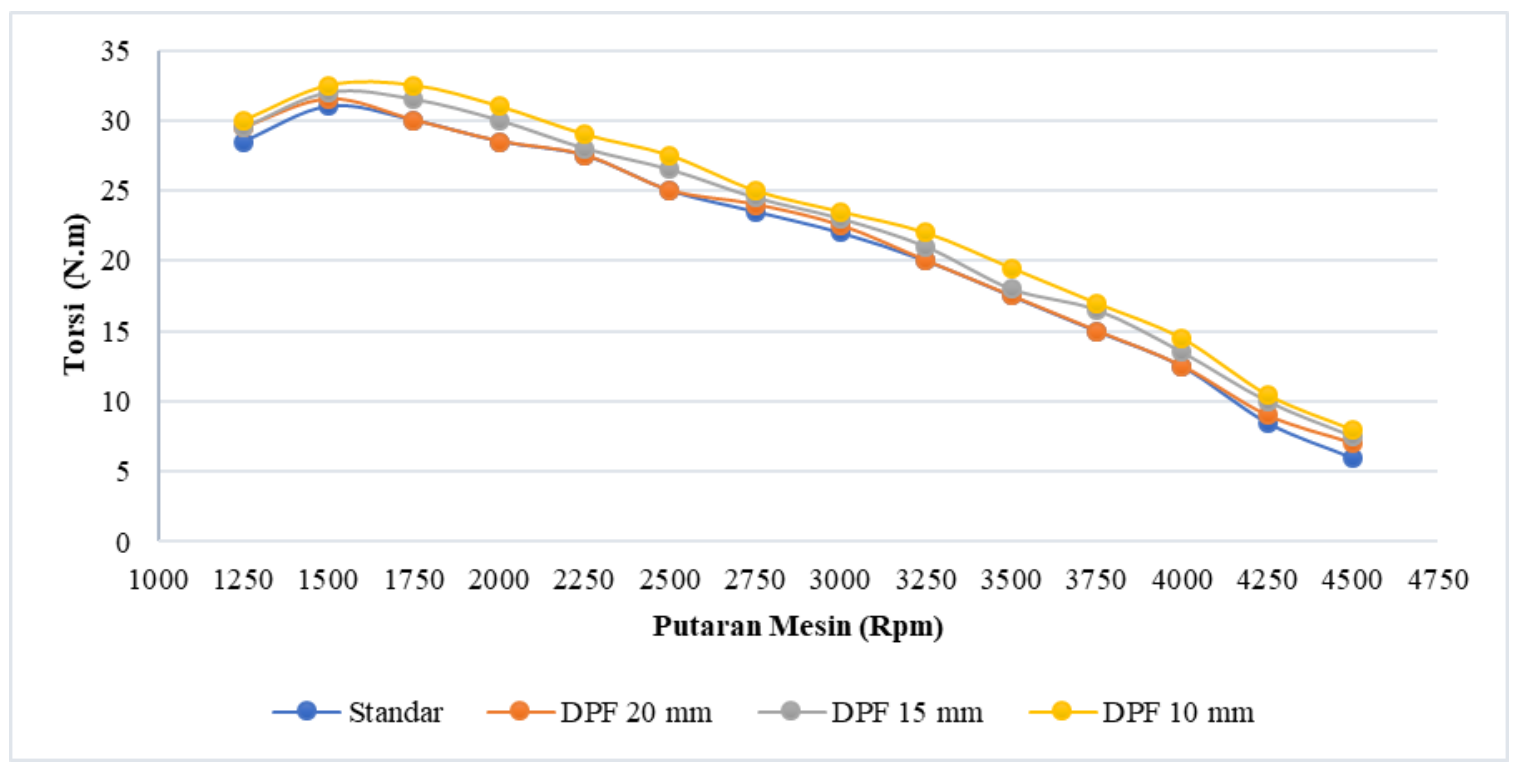

Gambar 4. Grafik Hubungan antara RPM dan Torsi

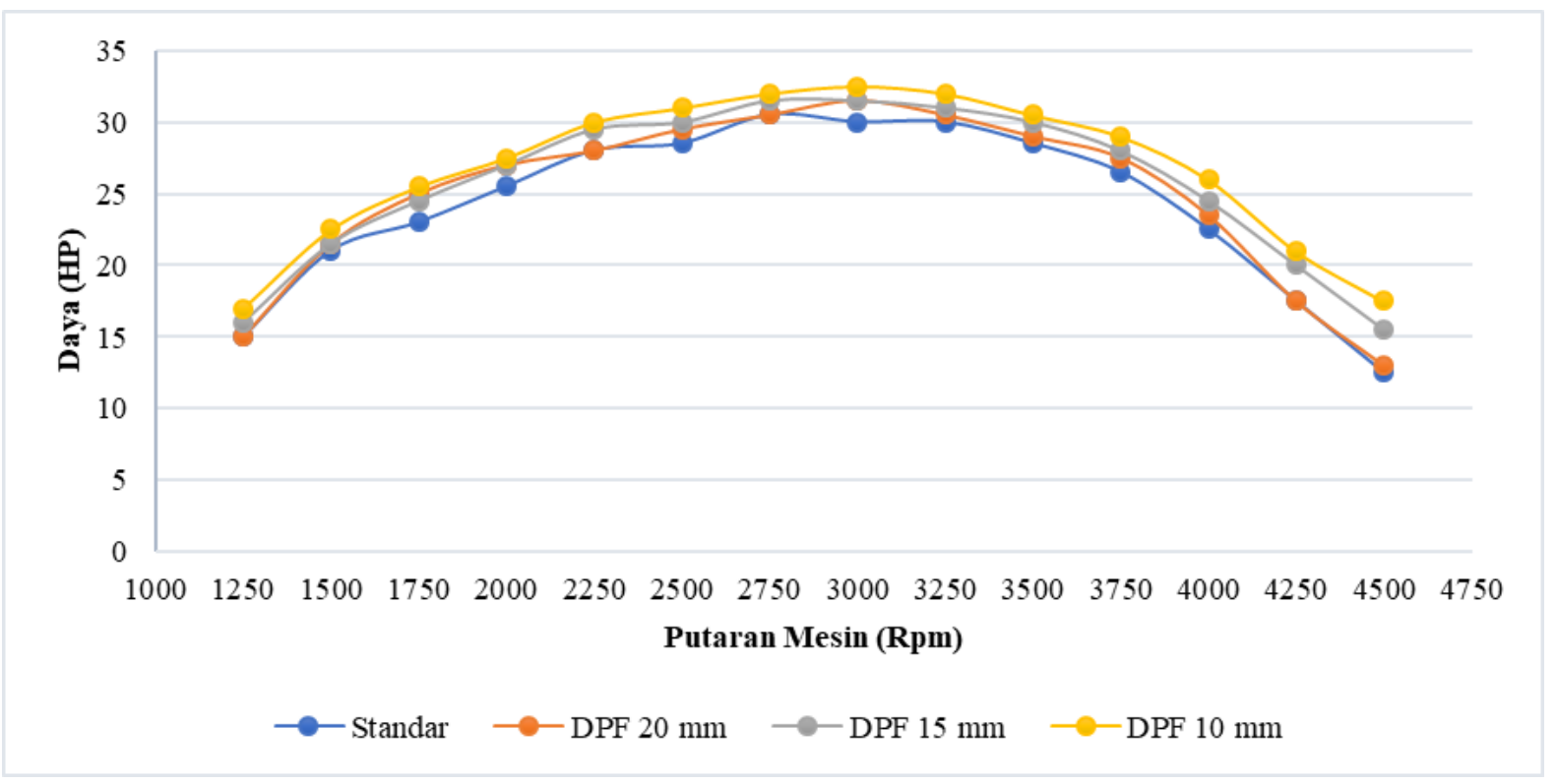

Gambar 5. Grafik Hubungan antara RPM dan Daya 
Tabel 4. Data Pengujian Daya

\begin{tabular}{|c|c|c|c|c|}
\hline \multirow[b]{2}{*}{$\begin{array}{l}\text { Putaran Mesin } \\
\text { (RPM) }\end{array}$} & \multicolumn{4}{|c|}{ Daya (HP) } \\
\hline & $\begin{array}{l}\text { Standar } \\
\text { (HP) }\end{array}$ & $\begin{array}{c}\text { DPF } \\
20 \mathrm{~mm} \\
(\mathrm{HP})\end{array}$ & $\begin{array}{c}\text { DPF } \\
15 \mathrm{~mm} \\
(\mathrm{HP})\end{array}$ & $\begin{array}{c}\text { DPF } \\
10 \mathrm{~mm} \\
(\mathrm{HP})\end{array}$ \\
\hline 1250 & 15 & 15 & 16 & 17 \\
\hline 1500 & 21 & 21,5 & 21,5 & 22,5 \\
\hline 1750 & 23 & 25 & 24,5 & 25,5 \\
\hline 2000 & 25,5 & 27 & 27 & 27,5 \\
\hline 2250 & 28 & 28 & 29,5 & 30 \\
\hline 2500 & 28,5 & 29,5 & 30 & 31 \\
\hline 2750 & 30,5 & 30,5 & 31,5 & 32 \\
\hline 3000 & 30 & 31,5 & 31,5 & 32,5 \\
\hline 3250 & 30 & 30,5 & 31 & 32 \\
\hline 3500 & 28,5 & 29 & 30 & 30,5 \\
\hline 3750 & 26,5 & 27,5 & 28 & 29 \\
\hline 4000 & 22,5 & 23,5 & 24,5 & 26 \\
\hline 4250 & 17,5 & 17,5 & 20 & 21 \\
\hline 4500 & 12,5 & 13 & 15,5 & 17,5 \\
\hline
\end{tabular}

\section{Berdasarkan}

Gambar 5, dapat kita ketahui bahwa selain mampu digunakan untuk mereduksi emisi PM dan meningkatkan torsi kendaraan, penggunaan teknologi DPF tipe honeycomb juga terbukti mampu meningkatkan daya pada mesin Isuzu Panther tahun 1996. Pada DPF mesh $20 \mathrm{~mm}$, daya meningkat rata-rata sebesar $2.94 \%$ bila dibandingkan dengan knalpot standar. Selanjutnya, pada DPF mesh 15 $\mathrm{mm}$ daya meningkat rata-rata sebesar $7.27 \%$ bila dibandingkan dengan knalpot standar. Kemudian, rata-rata peningkatan daya terbaik ada pada DPF mesh $10 \mathrm{~mm}$ dengan nila persentase sebesar $11.93 \%$ bila dibandingan dengan knalpot standar.

Penyebab utama terjadinya peningkatan daya adalah adanya peningkatan torsi akibat meningkatnya temperatur pada ruang bakar dan besarnya tekanan balik yang ditimbulkan oleh DPF tipe honeycomb [18]. Hasil penelitian ini sejalan dengan hasil penelitian Muliatna, Susila, \& Warju (2018) yang menunjukkan bahwa penggunaan diesel particulate trap (DPT) tipe wire mesh berbahan dasar stainless-steel mampu meningkatkan daya kendaraan meskipun tidak signifikan dengan persentase antara 5,37\% hingga 11,81\% [17]. Di samping itu, daya yang dihasilkan oleh DPF tipe honeycomb lebih baik bila dibandingkan dengan daya DPF tipe wire mesh yang menghasilkan persentase rata-rata daya sebesar $11,81 \%$ bila dibandingkan dengan knalpot standar.

\section{Kesimpulan}

Berdasarkan hasil pengujian, analisa, dan pembahasan ditemukan beberapa fakta sebagai berikut. Penggunaan DPF tipe honeycomb dengan mesh ukuran 20, 15, dan 10 $\mathrm{mm}$ dapat meningkatkan torsi rata-rata sebesar 2,29$11,68 \%$. Selain itu, penggunaan DPF tipe honeycomb dengan mesh ukuran 20, 15, dan $10 \mathrm{~mm}$ dapat meningkatkan daya mesin rata-rata sebesar 2,94-11,93\%. Dari ketiga variasi DPF tersebut, rata-rata peningkatan torsi terbaik terdapat pada DPF tipe honeycomb dengan mesh ukuran $10 \mathrm{~mm}$ yakni sebesar 11,68\%, dengan nilai torsi sebesar $32.5 \mathrm{~N} \cdot \mathrm{m}$. Sedangkan, rata-rata peningkatan daya terbaik juga terdapat pada DPF tipe honeycomb dengan mesh ukuran $10 \mathrm{~mm}$ yakni sebesar $11,93 \%$ dengan nilai daya sebesar 32,5 HP.

DPF tipe honeycomb dengan mesh ukuran $10 \mathrm{~mm}$ menjadi variasi terbaik dalam hal peningkatan performa mesin karena semakin kecil mesh maka proses penjebakan partikel debu halus akan semakin baik. Hal tersebut tentunya akan berdampak pada meningkatnya suhu di dalam DPF. Bell (1981) menjelaskan bahwa penggunaan desain DPF yang sesuai juga mutlak dibutuhkan. Hal tersebut bertujuan agar turbulensi aliran gas buang menjadi lebih rendah [14]. Kemudian, karena suhu yang terus meningkat dan turbulensi menjadi lebih rendah di dalam DPF memungkinkan terjadinya self-burning pada suhu kerja optimal DPF yang berkisar antara $300-500^{\circ} \mathrm{C}$ [13]. Oleh karena itu, torsi dan daya yang dihasilkan menjadi lebih meningkat jika dibandingkan dengan penggunaan knalpot standar.

\section{Daftar Pustaka}

[1] I. F. Nisa and Warju, "Pengaruh Variasi Bentuk Exhaust Manifold Pada Diesel Particulate Trap Berbahan Dasar Kuningan dan Wire Mesh Stainless Steel Terhadap Performa Mesin Diesel 4 Langkah," J. Tek. Mesin, vol. 7, no. 3, pp. 65-72, 2019.

[2] P. C. Kurniawan, "Analisis Kepatuhan Wajib Pajak Kendaraan Bermotor Berdasarkan Peraturan Gubernur No 44 Tahun 2017: Studi pada Badan Pengelola Pendapatan Daerah Provinsi Jawa Tengah," Jati J. Akunt. Terap. Indones., vol. 2, no. 1, 2019, doi: 10.18196/jati.020113.

[3] P. A. Hancock, I. Nourbakhsh, and J. Stewart, "On the future of transportation in an era of automated and autonomous vehicles," Proc. Natl. Acad. Sci., vol. 116, no. 16, pp. 7684-7691, Apr. 2019, doi: 10.1073/pnas. 1805770115.

[4] A. R. Pratama, J. Arliansyah, and M. Agustien, "Analysis of Air Pollution due to Vehicle Exhaust Emissions on The Road Networks of Beringin Janggut Area," J. Phys. Conf. Ser., vol. 1198, no. 8, p. 082030, Apr. 2019, doi: 10.1088/1742-6596/1198/8/082030.

[5] M. L. Burr, "Effects on respiratory health of a reduction in air pollution from vehicle exhaust emissions," Occup. Environ. Med., vol. 61, no. 3, pp. 212-218, Mar. 2004, doi: 10.1136/oem.2002.003244.

[6] D. Brugge, J. L. Durant, and C. Rioux, "Near-highway pollutants in motor vehicle exhaust: A review of epidemiologic evidence of cardiac and pulmonary health risks," Environ. Heal., vol. 6, no. 1, p. 23, Dec. 2007, doi: 10.1186/1476-069X-6-23.

[7] E. Dobrzyńska, M. Szewczyńska, M. Pośniak, A. Szczotka, B. Puchałka, and J. Woodburn, "Exhaust emissions from diesel engines fueled by different blends with the addition of nanomodifiers and hydrotreated vegetable oil HVO," Environ. Pollut., vol. 259, p. 113772, Apr. 2020, doi: 10.1016/j.envpol.2019.113772.

[8] S. R. Ariyanto and Warju, "Rancang Bangun Diesel Particulate Trap (DPT) Untuk Mereduksi Opasitas, Konsumsi Bahan Bakar, dan Tingkat Kebisingan Mesin Isuzu C190,” J. Rekayasa Mesin, vol. 01, no. 03, pp. 19-28, 2014.

[9] S. R. Ariyanto and Warju, "Unjuk Kemampuan Diesel Particulate Trap Berbahan Tembaga dan Glasswool Terhadap Reduksi Opasitas Gas Buang,” J. Otopro, vol. 11, 
no. May 2016, pp. 187-195, 2016.

[10] I. M. Muliatna, D. V. Wijanarko, and W. Warju, "Uji Efektivitas Diesel Particulate Trap (Dpt) Berbahan Dasar Kuningan Dan Glasswool Terhadap Reduksi Opasitas Gas Buang Mesin Diesel Multi Silinder," Otopro, vol. 13, no. 1, p. 35, Jun. 2019, doi: 10.26740/otopro.v13n1.p35-43.

[11] M. R. Ghufron and Warju, "Pengaruh Variasi Ukuran Wiremesh Stainless Steel pada Diesel Particulate Trap Terhadap Opasitas Gas Buang Mesin Isuzu Panther Tahun 2005," J. Tek. Mesin, vol. 7, no. 3, pp. 85-91, 2019.

[12] Warju, Teknologi Reduksi Emisi Gas Buang Kendaraan Bermotor, Pertama. Surabaya: Unesa University Press, 2013.

[13] J. B. Heywood, Internal Combustion Engine Fundementals, Internatio. New York: McGraw-Hill, 1988.
[14] A. G. Bell, Four-Stroke Performance Tuning in Theory and Practice. California: Haynes Publishing, 1981.

[15] SAE J1349, Engine Power Test Code-Spark Ignition and Compression Ignition-Net Power Rating. Warrendale: SAE International, 2004.

[16] W. W. Pulkrabek, Engineering Fundamentals of the Internal Combustion Engine, United Sta. Upper Saddle River, N.J: Prentice Hall, Inc., 2004.

[17] I. M. Muliatna, I. W. Susila, and Warju, "Pengaruh Diesel Particulate Trap (DPT) Tipe Wire Mesh Berbahan Dasar Stainless-Steel Terhadap Torsi dan Daya Mesin Diesel Multisilinder," in Prosiding Semnas PPM 2018, 2018, pp. 658-668.

[18] H. Heisler, Advanced Engine Technology. London: Chapman \& Hall, 1998. 